\title{
A inteligência emocional e social auxiliando o líder a atuar no ciclo de sucesso nas
} organizações de serviço

Emotional and social intelligence assisting the leader to act in the cycle of success in the service organizations

\section{Recebimento: 03/03/2020 - Aceite: 21/06/2020 - Publicação: 01/08/2020 \\ Processo de Avaliação: Double Blind Review}

Gabriel da Silva Campos ${ }^{1}$

Graduando em Administração na Faculdade Instituto Paulista de Ensino (FIPEN)

gabrieldasilvacampos@outlook.com

Maria Lúcia Gili Massi²

Doutora em Letras Clássicas

Professora da Faculdade Instituto Paulista de Ensino (FIPEN)

marialucia@ fipen.edu.br

\section{RESUMO}

As inteligências emocional e social têm sido muito abordadas no âmbito empresarial, destacando a necessidade de os líderes desenvolverem-nas, por serem eles as peças-chave para o ciclo de sucesso das organizações de serviço. Nessa direção, este artigo, baseado em pesquisas bibliográficas, em que foram explorados os componentes das inteligências emocional e social com foco no líder, pesquisando em periódicos científicos, sites e livros, sobretudo os de Goleman, tem como objetivo verificar a possibilidade de correlacionar as práticas do ciclo de sucesso das organizações de serviço com os componentes das inteligências emocional e social que o líder deve desenvolver. Ainda que haja muitas fontes de pesquisa sobre os temas desenvolvidos, nenhuma faz a correlação entre eles, o que evidencia a contribuição deste estudo com a academia. Os resultados revelaram que é possível correlacionar as práticas do ciclo de sucesso com as inteligências emocional e social que o líder deve desenvolver. Nessa

\footnotetext{
$1{ }^{1}$ Bolsista de Iniciação Científica apoiado pelo Conselho Nacional de Desenvolvimento Científico e Tecnológico - CNPq - Brasil. Autor para correspondência Fipen - Faculdade Instituto Paulista de Ensino: Rua Euclides da Cunha, 377, CEP 06016-030 - Osasco, SP, Brasil. E-mail.

E-mail:gabrieldasilvacampos@outlook.com

2 marialucia@fipen.edu.br
}

Revista ENIAC Pesquisa, Guarulhos (SP), V.9, n.2, ago.2020 - jan.2021 
perspectiva, este ensaio pode ser um guia de grande auxílio para a tomada de decisão dos líderes, colaborando assim com a sociedade.

Palavras-chave: Inteligência Emocional; Inteligência Social; Ciclo de sucesso nas organizações de serviço; Líder; Liderança.

\begin{abstract}
Intelligences emotional and social have been very boarded in the enterprise scope, detaching the necessity of the leaders develop-in, for being they them part-key for the cycle of success of the service organizations. In this direction, this article, based on bibliographical research, where the components of emotional and social intelligences with focus in the leader had been explored, searching in periodic scientific, sites and books, over all of Goleman, has as objective to verify the possibility to correlate the practical ones of the cycle of success of the organizations of service with the components of intelligences emotional and social that the leader must develop. Despite it has many sources of research on the developed subjects, none makes the correlation between them, what it evidences the contribution of this study with the academy. The results had disclosed that it is possible to correlate the practical ones of the cycle of success with intelligences emotional and social that the leader must develop. In this perspective, this assay can be a guide of great assists for the taking of decision of the leaders, thus collaborating with the society.
\end{abstract}

Keywords: Emotional intelligence; Social intelligence; Success cycle in the organizations of service; Leader; Leadership.

\title{
1. INTRODUÇÃO
}

Segundo Weisinger (1997), a inteligência emocional é o uso inteligente das emoções trabalhadas intencionalmente a favor do indivíduo, ditando o comportamento e o raciocínio, para obtenção de resultados equilibrados. Nesse contexto, a inteligência emocional é utilizada tanto intrapessoalmente - para ajudar a si próprio, como interpessoalmente - para ajudar outras pessoas. Thorndike, (1920, apud Goleman, 2011) definiu o termo 'inteligência social' como "a habilidade de entender e administrar homens e mulheres, meninos e meninas, para agir sabiamente nas relações humanas".

Revista ENIAC Pesquisa, Guarulhos (SP), V.9, n.2, ago.2020 - jan.2021 
Ambas, inteligência emocional e inteligência social, possuem componentes que ajudam o indivíduo a desenvolver relacionamentos harmoniosos, e um dos profissionais que mais necessitam dessas habilidades são os líderes, pois eles precisam dessa expertise para atuar de forma criativa e focada em resultados (SBIE.COM., 2019). Bons líderes sabem suas obrigações, excelentes líderes estão preparados para as diversas situações, previsíveis ou imprevisíveis, e é nesse momento que a inteligência emocional e a inteligência social agem formando líderes resistentes e preparados (Goleman, 2016).

Baseado na complexidade do papel do líder foi determinado o problema que deu causa a este estudo: é possível correlacionar as práticas do ciclo de sucesso das organizações de serviço com os componentes das inteligências emocional e social que o líder deve desenvolver para tomar decisões eficazes?

O ciclo de sucesso das organizações de serviço reflete a qualidade da cadeia formada entre a atuação do líder, o liderado e o cliente. Há uma vinculação entre o tratamento que o líder despende ao liderado e o tratamento que esse liderado vai dispensar ao cliente, ou seja, se o liderado for gerido com práticas que promovam o seu desenvolvimento e qualidade de vida, ele, satisfeito com o líder, com o trabalho e com a organização, entregará, ao cliente, sua satisfação, mediante um atendimento atencioso, proativo e empático (LOVELOCK \& WIRTZ, 2011).

Com esse entendimento, este estudo contribuirá com a academia uma vez que não foi encontrada literatura voltada para a atuação do líder e o ciclo de sucesso nas organizações de serviços, tendo como base os componentes da inteligência emocional e social. Nessa perspectiva, ao correlacionar as práticas do ciclo de sucesso com os componentes das inteligências emocional e social, este estudo contribuirá também com a sociedade, pois poderá ajudar os líderes a tomar decisões eficazes.

Para atingir seu objetivo, que é verificar a possibilidade de correlacionar as práticas do ciclo de sucesso das organizações de serviço com os componentes das inteligências emocional e social que o líder deve desenvolver, este artigo está estruturado em sete seções. Nesta primeira seção, está a introdução. Na segunda, será apresentada a fundamentação teórica. Na terceira, será descrita a metodologia; na quarta, serão apresentados os resultados e discussão; na quinta seção, serão feitas as considerações finais, na sexta seção estão os agradecimentos, e, na última seção, estão relacionadas as fontes de pesquisa.

Revista ENIAC Pesquisa, Guarulhos (SP), V.9, n.2, ago.2020 - jan.2021 


\section{FUNDAMENTAÇÃO TEÓRICA}

As propostas para um novo modelo de gestão de pessoas coloca sobre o líder a responsabilidade por mediar o atendimento entre as expectativas das empresas e dos empregados (DUTRA ET AL., 2017), e, para o desempenho desse papel complexo, a inteligência acadêmica não oferece o preparo necessário, pois um Coeficiente de Inteligência (QI) alto não garante as competências necessárias para o enfrentamento dos desafios, uma vez que as escolas privilegiam o desenvolvimento das competências acadêmicas e ignoram os traços que formam a inteligência emocional, decisiva para prosperar em caminhos tortuosos (GOLEMAN, 2012).

O indivíduo emocionalmente inteligente é aquele que consegue identificar e administrar as suas emoções, ações que remetem ao conceito de razão, ou seja, à faculdade de raciocinar, avaliar, julgar ou ponderar ideias, para assim estabelecer relações lógicas (BUARQUE, 2001). O termo "emoção" vem do latim 'emovere', onde o ' $e$ ' é uma preposição que tem a ideia de movimento de dentro para fora, enquanto o 'movere' significa movimento, formando, desse modo, um movimento do interior das pessoas para fora. $\mathrm{O}$ termo inteligência emocional forma um oxímoro, pois relaciona palavras de sentidos opostos, que parecem excluir-se, mas que juntas exprimem um único conceito (GARCIA, 2010).

Segundo Fonseca, 2017, as emoções são um conjunto de respostas químicas e neurais baseadas nas memórias emocionais, e surgem quando o cérebro recebe um estímulo externo a partir das rotas neurais e hormonais.

O líder de sucesso, segundo Goleman, 2015, deve desenvolver as habilidades emocionais e sociais. Para o autor, o termo inteligência social não se resume em aprender a teoria dessa habilidade, mas agir dessa forma nos relacionamentos. $\mathrm{O}$ foco da inteligência social amplia a visão de uma pessoa para duas pessoas, das habilidades de um indivíduo para as habilidades que se desenvolvem quando uma pessoa se envolve em um relacionamento. Expandir o foco permite olhar além do indivíduo, para entender o que realmente transpira quando as pessoas interagem, e olhar além dos interesses individuais para enxergar os interesses do outro (GOLEMAN, 2011).

Se o desenvolvimento das inteligências emocional e social são necessárias para qualquer profissional auto motivar-se, apesar dos percalços; controlar seus impulsos; impedir que a Revista ENIAC Pesquisa, Guarulhos (SP), V.9, n.2, ago.2020 - jan.2021 
ansiedade interfira na capacidade de raciocinar, e de ser empático e confiante, para o líder, essas habilidades são essenciais (GOLEMAN, 2012), pois a liderança é um fenômeno exclusivo de grupos sociais. Chiavenato, 2012, define a liderança como uma influência interpessoal exercida em dada situação e dirigida pelo processo de comunicação para a consecução de um ou mais objetivos. Para Goleman, 2019, liderança é a capacidade de guiar e inspirar indivíduos ou grupos em direção a uma visão. Drucker, 2001, afirma que a liderança pode ser nata ou aprendida. $\mathrm{O}$ indivíduo interessado em se tornar líder deve buscar qualificação para ser capaz de identificar os meios de motivar sua equipe de forma consistente, almejando ultrapassar as expectativas da organização e dos empregados (DUTRA ET AL., 2017).

Existem diferentes estilos de liderança, e os líderes mais eficazes mudam de estilo quando necessário. Para Goleman, 2019, os estilos podem ser: a) coercitivo - o líder exige imediata obediência, conduz à execução de tarefas, cria iniciativas, e na totalidade do tempo possui o autocontrole de tudo; b) autoritário - o líder mobiliza a equipe na direção de uma visão comum, concentrando-se nos objetivos finais, mas sem dizer como cada indivíduo deve chegar lá; c) agregador - o líder cria harmonia e constrói laços emocionais, possui empatia, constrói relacionamentos e estabelece comunicação; d) democrático - o líder busca o consenso por meio da participação, possui interesse no que seus subordinados pensam; e) conselheiro - o líder desenvolve pessoas para o futuro, busca caminhos diferentes para alcançar os objetivos da organização, e tem como base a empatia e a autoconsciência; f) agressivo - o líder estabelece altos padrões de desempenho e ordena que faça como ele no exato momento solicitado; g) transformacional - o líder é obsessivo em fazer as coisas melhor e mais rápidas, e pede o mesmo para todos que estão ao seu redor, esse líder rapidamente aponta desempenhos fracos e exige mais.

Segundo Oliveira, 1997 apud Filho \& Goes, 2008, liderar é exercer alguma forma de poder, e o poder é a capacidade de influenciar alguém. Para Hunter, 2004, apud Filho \& Goes, 2008, a liderança é a habilidade de influenciar pessoas para trabalharem com entusiasmo, visando atingir os objetivos identificados para o bem comum. Neto \& Calvosa, 2001 apud Filho e Goes, 2008, dizem que liderar é a arte de conseguir com que as pessoas façam algo, ou busquem resultados, por meio da confiança, admiração e vontade própria, motivados por um ideal ou por um objetivo que as organizações tentam alcançar. Para Ervilha, 2008 apud Filho \& Goes, 2008, liderar é influenciar e conduzir pessoas nas situações em que é identificado um objetivo claro e definido, que busca os resultados desejados.

Revista ENIAC Pesquisa, Guarulhos (SP), V.9, n.2, ago.2020 - jan.2021 
Ainda que haja muitas definições de liderança e que muitos autores brasileiros abordem o tema, essa é, segundo Dutra et al. 2017, uma discussão recente no Brasil. Até os anos de 1990, devido ao baixo nível de competitividade das empresas, o líder caracterizava-se por ser um bom técnico. A partir de 1990, as lideranças procuraram se preparar para atuarem em um mercado mais exigente, investindo em seu desenvolvimento como gestores. As pesquisas sobre liderança no Brasil revelam que o grande problema da liderança, no presente, é comportamental, tais como: comunicação, lidar com a diversidade, delegação e construção de parcerias internas e externas

A realidade brasileira, segundo Dutra et al. 2017, é muito particular no que se refere à forma como as lideranças foram desenvolvidas. Desde o início do século 20, elas têm participação ativa na construção da cultura, política e economia, mas, ao mesmo tempo, elas têm como característica um comportamento autoritário e paternalista. Hoje, os consultores que atuam com o desenvolvimento de liderança dizem que as lideranças brasileiras têm uma boa formação técnica e em gestão de negócios, entretanto, em muitas organizações, há uma excessiva valorização do técnico como líder, e de um comportamento autoritário e paternalista (DUTRA ET AL., 2017).

Diante das pressões impostas às organizações brasileiras e de um futuro mais exigente, segundo Dutra et al. 2017, as lideranças brasileiras necessitam ampliar sua capacidade para gerenciar pessoas, criando e sustentando equipes de alta performance. Para tanto, elas têm como principal ponto de desenvolvimento suas habilidades comportamentais.

Nesse sentido, Goleman, 2012, diz que os fatores comportamentais são tão importantes quanto o controle das emoções. Não é de hoje, diz o autor, que percebemos que um líder sem inteligência emocional e social não consegue tomar decisões em momentos críticos ou de alta pressão, isso só comprova que trabalhar essas habilidades cerebrais é de suma importância para o sucesso da empresa (GOLEMAN, 2018).

A Inteligência emocional consiste na habilidade de gerenciar eficazmente as emoções e os relacionamentos humanos, para isso, Goleman, 2012, afirma que as pessoas carecem de duas competências: competência pessoal e competência social, cada uma com suas capacidades e características fundamentais. As competências pessoais são: a) auto-percepção - capacidade do indivíduo conhecer seu estado interior, suas preferências e intuições; b) percepção emocional capacidade de o indivíduo conhecer como as emoções podem afetar seu desempenho não só no trabalho, mas no dia a dia, e, como seus valores podem guiá-lo na tomada de decisão; c) auto-

Revista ENIAC Pesquisa, Guarulhos (SP), V.9, n.2, ago.2020 - jan.2021 
avaliação - capacidade de o indivíduo avaliar seus pontos fortes e fracos e analisar suas capacidades e limitações. Pessoas com essa capacidade são capazes de refletir e aprender com as experiências, mostrando-se abertas a comentários francos, e olhares com novas perspectivas, em busca de novos aprendizados e autodesenvolvimento; mostram senso de humor e possuem uma visão crítica sobre si mesmas; d) autoconfiança: capacidade de o indivíduo ter forte senso do próprio valor e da própria capacidade. Pessoas com essas capacidades se apresentam de maneira segura, mostrando presença, sendo capazes de expressar opiniões diferentes da maioria e de se expor por algo que considere correto; são decididas, capazes de tomar decisões sensatas, mesmo à mercê de incertezas e pressões (GOLEMAN, 2012).

A eficácia da inteligência emocional do líder, e o consequente êxito das organizações, para Goleman, 2015 apud Maciel \& Sousa, 2016, fundamentam-se em quatro componentes: a) autoconsciência - consiste na autoconsciência emocional, na auto-avaliação e na autoconfiança; b) autogestão - consiste no autocontrole, na confiança, no estado consciente, na adaptabilidade e iniciativa; c) empatia - consiste na tentativa de se colocar no lugar do próximo, sentir o que a pessoa está sentindo em determinado momento; d) habilidade social - consiste em: liderança visionária, influência, desenvolvimento de pessoas, comunicação, mudança catalisadora, gestão de conflitos, construção de laços, trabalho em equipe e colaboração.

Goleman, 2012, enfatiza que as pessoas que possuem as competências emocionais conhecem as emoções que sentem e o porquê, conseguem relacionar seus sentimentos, o que pensam, fazem e dizem, sendo verdadeiras, e reconhecem como seus sentimentos, uma vez descontrolados, podem afetar seu desempenho, e, nessa ocorrência, as competências emocionais, como uma percepção orientadora, os direciona para agir conforme os seus valores e objetivos.

Para Weisinger, 1997, a inteligência emocional nasce de quatro componentes: a) capacidade de perceber, avaliar e expressar a emoção corretamente; b) capacidade de gerar ou sentir as emoções de forma que isso facilite a compreensão de si mesmo e do que está sentindo; c) capacidade de compreender e aprender com cada emoção; d) capacidade de controlar as emoções em busca do crescimento emocional e intelectual.

Investir tempo e esforço intelectual para desenvolver os quatro pilares da inteligência emocional é de suma importância para qualquer ser humano que deseje uma evolução constante, e, em especial, para os líderes que necessitam dessas habilidades para tomar decisões (GOLEMAN, 2000 APUD MACIEL \& SOUZA, 2016). Ambientes com clima pesado de

Revista ENIAC Pesquisa, Guarulhos (SP), V.9, n.2, ago.2020 - jan.2021 
trabalho e com um líder compassivo aos resultados inesperados proporciona desestabilidade na equipe, afetando diretamente os resultados (ZONIS, 2016).

Líderes com bons relacionamentos interpessoais têm maior poder e influência sobre os liderados, e quanto melhor a relação, mais favorável é a influência (LUSSIER \& ACHUA, 2004), por isso, precisam desenvolver a inteligência social. O desenvolvimento dessa inteligência assenta-se nos seguintes componentes: a) influência - capacidade de utilizar instrumentos eficazes de persuasão; b) comunicação - capacidade de ouvir abertamente e enviar mensagens convincentes; c) liderança - capacidade de guiar e inspirar indivíduos ou grupos em direção a uma visão; d) catalisador de mudanças - capacidade de iniciar ou gerenciar mudanças; e) gerenciamento de conflitos - capacidade de negociar e solucionar discordâncias; f) estabelecimento de vínculos: capacidade de cuidar de relacionamentos instrumentais; g) colaboração e cooperação: capacidade de trabalhar com outras pessoas buscando atingir metas comuns; f) capacidade de equipe: criar sinergia ao trabalhar na direção de metas coletivas (GOLEMAN, 2019).

O líder deve dominar a inteligência emocional e social para lidar com sua equipe, desenvolvendo a empatia, reconhecendo as emoções dos outros, observando como os indivíduos veem as coisas, como se sentem, e usando essas informações em suas interações da forma mais eficaz. Ao trabalhar essas competências, o líder será mais persuasivo e os liderados mais motivados (GOLEMAN, 2018, APUD PORTAL DA LIDERANÇA, 2016).

O resultado do desempenho do líder na condução da equipe que atua na linha de frente, nas organizações de serviço, é exposto no ciclo de atuação da empresa, que pode ser de fracasso, mediocridade ou de sucesso. Ambientes de trabalho ruins, com altas taxas de rotatividade, traduzem-se em serviços pavorosos, com empregados que tratam os clientes como são tratados. Contudo, se a empresa for bem liderada, o potencial para atuação no ciclo de sucesso é grande (LOVELOCK ET AL., 2011).

O ciclo de sucesso de uma organização de serviço depende da adoção de uma visão de longo prazo para o desempenho financeiro, pois a empresa vai prosperar por meio do investimento em seus empregados, pois a satisfação e a fidelização dos clientes, e o consequente êxito da empresa, dependem da satisfação dos empregados (LOVELOCK ET AL., 2011).

Há uma simbiose entre o ciclo de satisfação do empregado e o ciclo de satisfação do cliente, sendo um ciclo interativo e concêntrico ao outro. Para a criação do ciclo de sucesso, as organizações de serviço devem ter boas práticas de gestão de pessoas, dentre as quais se

Revista ENIAC Pesquisa, Guarulhos (SP), V.9, n.2, ago.2020 - jan.2021 
destacam: oferecer pacotes atraentes de remuneração para atrair pessoas bem qualificadas; manter descrições de cargos menos limitadas, e acompanhadas por treinamento e práticas de empowerment que permitam ao pessoal da linha de frente controlar a qualidade do serviço. Com recrutamento mais focalizado, treinamento intensivo e melhores salários, é provável que os empregados fiquem mais satisfeitos e ofereçam um serviço mais agradável e de qualidade superior, aos clientes, que apreciam a continuidade dos relacionamentos, graças à baixa rotatividade dos empregados, e ficam mais propensos a permanecer fiéis. Margens de lucro tendem a ser mais altas, e a organização fica livre para concentrar seus esforços de marketing no reforço da fidelização por meio de estratégias de retenção de clientes, que costumam ser mais lucrativas do que as de atração de novos consumidores (LOVELOCK ET AL., 2011).

Com essa perspectiva, este estudo se propõe a verificar a possibilidade de correlacionar as práticas do ciclo de sucesso das organizações de serviço com os componentes das inteligências emocional e social que o líder deve desenvolver.

\section{METODOLOGIA:}

A abordagem metodológica deste artigo consistiu em pesquisas bibliográficas, sobretudo em livros e em periódicos científicos, para explorar os componentes da inteligência emocional e da inteligência social com foco no líder, correlacionando esses componentes com as práticas do ciclo de sucesso das organizações de serviço.

Exploradas, na literatura, as ações voltadas para as pessoas que tornam as empresas de serviço bem sucedidas, bem como as premissas que norteiam tais atos, o passo seguinte foi levantar os componentes das inteligências emocional e social com foco no líder.

A maior parte dos cargos de liderança, refere a literatura, é ocupada por indivíduos que apresentam melhor gerenciamento de suas emoções. Gerenciar emoções é terreno da inteligência emocional. Assim, o que muitas empresas têm feito na prática, sem domínio dos conhecimentos teóricos, encontra sustentação no campo da pesquisa científica, e este estudo se propôs a mostrar a correlação que pode haver entre os componentes das inteligências emocional e social e os componentes do ciclo de sucesso das organizações de serviço, por meio da análise do conteúdo de cada componente e sua aproximação com o outro. Desse modo, o Quadro 1 Correlação entre as práticas do ciclo de sucesso e os componentes da inteligência emocional e social, é o resultado de uma análise aprofundada pelos autores entre os conceitos teóricos apreendidos na literatura consultada que se mostraram praticáveis.

Revista ENIAC Pesquisa, Guarulhos (SP), V.9, n.2, ago.2020 - jan.2021 


\section{RESULTADOS E DISCUSSÃO}

Trabalhar no ciclo de sucesso significa que o líder deve atuar com as práticas de gestão de pessoas seguintes (LOVELOCK ET AL., 2011):

a) Ser o empregador preferido - não precisa ser um dos melhores pagadores, se outros aspectos forem atraentes, como, por exemplo, tiver uma boa imagem de bom empregador na comunidade e entregar produtos e serviços de alta qualidade, que façam os empregados sentirem orgulho de serem parte da equipe.

b) Contratar as pessoas certas - competir no mercado de trabalho pelas pessoas certas significa propor uma remuneração acima da média de mercado ou oferecer um ambiente de trabalho atraente.

c) Selecionar as pessoas certas - que tenham diferentes conjuntos de habilidades, estilos e personalidades, que tenham qualidades intrínsecas, que não podem ser ensinadas, tais como: cordialidade; energia e ética no trabalho.

d) Treinar exaustivamente - empregados de serviço precisam ser treinados em:

- Cultura, objetivo e estratégia da organização;

- Habilidades interpessoais e técnicas;

- $\quad$ Conhecimento de produto/serviço.

e) Utilizar todo o leque de recompensas, tais como: salário, bônus, conteúdo do trabalho, atingimento de metas, feedback e reconhecimento.

f) Dar autonomia ao pessoal da linha de frente, empoderando-os para decidir quando estiverem face a face com os clientes.

g) Reduzir o tournover.

Sendo essas as responsabilidades da liderança, para que as organizações operem no ciclo de sucesso, correlacionar tais responsabilidades aos componentes da inteligência emocional e social, conforme Quadro 1, poderá ajudar o líder a obter os resultados esperados. 
Quadro 1 - Correlação entre as práticas do ciclo de sucesso e os componentes da inteligência emocional e social.

\begin{tabular}{|c|c|c|c|}
\hline $\begin{array}{l}\text { Práticas do ciclo } \\
\text { de sucesso }\end{array}$ & $\begin{array}{c}\text { Premissas para execução das } \\
\text { práticas }\end{array}$ & $\begin{array}{l}\text { Componentes de } \\
\text { IE }\end{array}$ & Componentes da IS \\
\hline $\begin{array}{l}\text { Seja o empregador } \\
\text { preferido. }\end{array}$ & $\begin{array}{l}\text { Projete imagem de bom } \\
\text { empregador, entregando serviços } \\
\text { de alta qualidade, que façam os } \\
\text { empregados se orgulharem de } \\
\text { fazer parte da equipe. }\end{array}$ & $\begin{array}{l}\text { Auto-consciência } \\
\text { e } \quad \text { habilidade } \\
\text { social. }\end{array}$ & $\begin{array}{l}\text { Estabelecimento de vínculos, } \\
\text { influência e liderança. }\end{array}$ \\
\hline $\begin{array}{l}\text { Selecione a pessoa } \\
\text { certa. }\end{array}$ & $\begin{array}{l}\text { Certa é a pessoa dotada de valores } \\
\text { intangíveis para satisfazer o } \\
\text { cliente. }\end{array}$ & $\begin{array}{l}\text { Auto-percepção e } \\
\text { habilidade social. }\end{array}$ & $\begin{array}{l}\text { Capacidade de equipe } \mathrm{e} \\
\text { estabelecimento de vínculos. }\end{array}$ \\
\hline $\begin{array}{l}\text { Treine cultura } \\
\text { organizacional. }\end{array}$ & $\begin{array}{l}\text { Apresente os comportamentos que } \\
\text { a organização valoriza. }\end{array}$ & $\begin{array}{l}\text { Empatia e } \\
\text { habilidade social. }\end{array}$ & 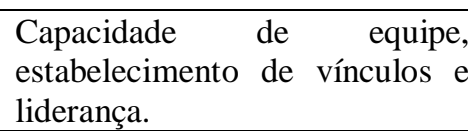 \\
\hline $\begin{array}{lr}\text { Treine } & \text { em } \\
\text { objetivo } & \mathrm{e} \\
\text { estratégia. } & \end{array}$ & $\begin{array}{l}\text { Mostre caminhos para chegar onde } \\
\text { a empresa espera. }\end{array}$ & $\begin{array}{l}\text { Empatia e } \\
\text { habilidade social. }\end{array}$ & $\begin{array}{l}\text { Capacidade. de } \text { equipe, } \\
\text { estabelecimento de vínculos e } \\
\text { liderança. }\end{array}$ \\
\hline $\begin{array}{l}\text { Treine as } \\
\text { habilidades } \\
\text { interpessoais. }\end{array}$ & $\begin{array}{l}\text { Seja o exemplo de como um bom } \\
\text { relacionamento promove a união } \\
\text { e o bom desempenho da equipe. }\end{array}$ & $\begin{array}{l}\text { Empatia e } \\
\text { habilidade social. }\end{array}$ & $\begin{array}{l}\text { Comunicação, influência e } \\
\text { liderança. }\end{array}$ \\
\hline Treine as técnicas. & Apresente as melhores práticas. & $\begin{array}{l}\text { Empatia e } \\
\text { habilidade social. }\end{array}$ & $\begin{array}{l}\text { Capacidade } \text { de equipe, } \\
\begin{array}{l}\text { catalisador de mudanças e } \\
\text { liderança. }\end{array}\end{array}$ \\
\hline $\begin{array}{l}\text { Treine em } \\
\text { conhecimento de } \\
\text { produto/serviço. }\end{array}$ & $\begin{array}{l}\text { Forneça exemplos de como o } \\
\text { serviço deve ser realizado, } \\
\text { mostrando o processo do input } \\
\text { (entrada) ao output (saída). }\end{array}$ & $\begin{array}{l}\text { Empatia e } \\
\text { habilidade social. }\end{array}$ & $\begin{array}{l}\text { Capacidade de equipe, } \\
\text { colaboração, comunicação, } \\
\text { cooperação, estabelecimento de } \\
\text { vínculos influência, e liderança. }\end{array}$ \\
\hline $\begin{array}{l}\text { Conteúdo } \\
\text { trabalho. }\end{array}$ & $\begin{array}{l}\text { Os cargos devem ser amplos e } \\
\text { flexíveis, permitindo que a pessoa } \\
\text { amplie o nível de complexidade de } \\
\text { suas atribuições. }\end{array}$ & $\begin{array}{l}\text { Empatia e } \\
\text { habilidade Social. }\end{array}$ & $\begin{array}{llll}\text { Capacidade } & \text { de } & \text { equipe } & \mathrm{e} \\
\text { liderança. } & & & \\
\end{array}$ \\
\hline $\begin{array}{l}\text { Dê autonomia à } \\
\text { linha de frente. }\end{array}$ & Pratique o empowerment. & $\begin{array}{l}\text { Auto-avaliação e } \\
\text { auto-percepção. }\end{array}$ & $\begin{array}{l}\text { Capacidade de } \\
\text { colaboração equipe, } \\
\begin{array}{l}\text { estabelecimento de } \\
\text { liderança. }\end{array}\end{array}$ \\
\hline Feedback. & $\begin{array}{l}\text { Seja sincero e oportuno, baseado } \\
\text { no comportamento do liderado. }\end{array}$ & $\begin{array}{l}\text { Auto-avaliação, } \\
\text { empatia e } \\
\text { habilidade social. }\end{array}$ & $\begin{array}{l}\text { Catalisador de mudanças, } \\
\text { comunicação, gerenciamento de } \\
\text { conflitos, influência e liderança. }\end{array}$ \\
\hline $\begin{array}{l}\text { Reconheça os } \\
\text { bons } \\
\text { desempenhos }\end{array}$ & $\begin{array}{l}\text { Valorize mediante salário, bônus, } \\
\text { elogio, promoção. }\end{array}$ & $\begin{array}{l}\text { Auto-avaliação, } \\
\text { empatia e } \\
\text { habilidade social. }\end{array}$ & $\begin{array}{l}\text { Colaboração, cooperação, } \\
\text { comunicação, influência e } \\
\text { liderança. }\end{array}$ \\
\hline $\begin{array}{l}\text { Motive e energize } \\
\text { o pessoal. }\end{array}$ & $\begin{array}{l}\text { Mostre o senso de missão. } \\
\text { Diagnostique as necessidades da } \\
\text { equipe e as satisfaça. }\end{array}$ & $\begin{array}{l}\text { Autogestão,empat } \\
\text { ia e habilidade } \\
\text { social. }\end{array}$ & Comunicação e influência \\
\hline $\begin{array}{l}\text { Atingimento de } \\
\text { Metas. }\end{array}$ & $\begin{array}{l}\text { Norteie o desempenho para o } \\
\text { atingimento de metas, conciliando } \\
\text { as expectativas da empresa, do } \\
\text { empregado e do cliente. }\end{array}$ & $\begin{array}{l}\text { Autoconfiança e } \\
\text { habilidade social }\end{array}$ & $\begin{array}{l}\text { Capacidade de equipe, } \\
\text { colaboração e cooperação. }\end{array}$ \\
\hline $\begin{array}{l}\text { Reduza } \\
\text { rotatividade. }\end{array}$ & $\begin{array}{l}\text { Aja para conciliar as expectativas } \\
\text { dos empregados e da empresa. }\end{array}$ & $\begin{array}{l}\text { Auto-avaliação, } \\
\text { auto-percepção e } \\
\text { habilidade social. }\end{array}$ & $\begin{array}{l}\text { Comunicação, gerenciamento de } \\
\text { conflitos, Influência, e liderança. }\end{array}$ \\
\hline
\end{tabular}

Fonte: Elaborado pelo autor.

Revista ENIAC Pesquisa, Guarulhos (SP), V.9, n.2, ago.2020 - jan.2021 
A maior parte dos cargos de liderança não é ocupado por pessoas que possuem os maiores QIs, mas por aqueles que apresentam melhor gerenciamento de suas emoções. Esse atributo redefine o conceito de gestão e traz vantagem competitiva para as empresas, pois direciona os empregados para o alcance de metas e aumento da produtividade com qualidade de vida no trabalho (SILVA, 2016).

\section{CONSIDERAÇÕES FINAIS}

Com o passar dos anos, um novo modelo de gestão de pessoas foi se desenvolvendo, e, nele, o líder auferiu a responsabilidade de mediar o atendimento das expectativas entre a organização e os colaboradores. A responsabilidade que lhe foi atribuída, evidencia que, além de possuir os conceitos teóricos sobre como realizar o serviço, o líder precisa possuir e utilizar as inteligências emocional e social, que lhe conferem habilidades para os momentos críticos e de alta pressão.

Empresas com líderes robustos emocionalmente e socialmente tendem a ser mais fortes, transmitindo essa segurança para os colaboradores da equipe. Com essas habilidades desenvolvidas, o líder pode analisar cada situação, previsível ou imprevisível, e agir com temperança e assertividade.

Diante do que foi apresentado neste estudo, é primordial que os líderes trabalhem essas habilidades cerebrais para que suas inseguranças não ameacem as organizações de serviço e auxiliem para que elas operem no ciclo de sucesso.

Após analisar as pesquisas teóricas realizadas e tendo como base o Quadro 1, apresentado na seção Resultados e Discussão, é concebível inferir que a inteligência emocional e a inteligência social podem sim auxiliar o líder na execução das práticas do ciclo de sucesso das organizações de serviço, tornando essas habilidades primordiais para alcançar tais feitos.

Como este estudo se restringiu ao âmbito teórico, é oportuno sugerir uma pesquisa de campo para identificar na prática a correlação entre os conceitos.

Ao apresentar, no Quadro 1, a correlação entre as práticas do ciclo de sucesso com os componentes das inteligências emocional e social, que o líder deve desenvolver, é possível concluir que o objetivo que norteou este estudo foi atingido.

Revista ENIAC Pesquisa, Guarulhos (SP), V.9, n.2, ago.2020 - jan.2021 


\section{REFERÊNCIAS}

BUARQUE, A. O mini dicionário da língua portuguesa (4 ed.). Rio de Janeiro: Editora Nova Fronteira S.A, 2001.

CHIAVENATO, I. Administração Geral e Pública (3 ed.). Editora Monale. Barueri, SP, 2012.

DUTRA, J. S., DUTRA, T. A., DUTRA, G. A. Gestão de Pessoas: Realidade atual e desafios futuros. São Paulo: Atlas, 2017

DRUCKER, P. Administrando para o Futuro: os anos 90 e a virada do século. São Paulo: Pioneira Thomson Learning, 2001

FILHO, J. G. L., \& GOES, G. A. Liderança para gestão de pessoas: O líder que as empresas procuram (2001). Disponível em http://www.convibra.org/upload/paper/2013/34/2013_34_7682.pdf, acesso 02 Dez. 2018.

FONSECA, R. Conheça a definição de emoção. Segundo Rodrigo Fonseca. Sociedade Brasileira de Inteligência Emocional (SBIE) (2017). Disponível em http://www.sbie.com.br/blog/conheca-definicao-de-emocao/ acesso 04 de Nov. 2018

GARCIA, O. M. Comunicação em prosa moderna: aprender a escrever, aprendendo a pensar (27a . ed.). Rio de Janeiro: Editora FGV, 2010

GOLEMAN, D. Inteligência Social (recurso eletrônico): o poder das relações humanas. Tradução Ana Beatriz Rodrigues. Rio de Janeiro: Elsevier, 2011

GOLEMAN, D. Inteligência Emocional: A teoria revolucionária que redefine o que é ser inteligente. Editora Objetiva. Rio de Janeiro, 2012

GOLEMAN, D. Liderança com a inteligência emocional. Mettodo (2012). Disponível em http://www.mettodo.com.br/pdf/Lideran\%C3\%A7a\%20com\%20a\%20Intelig\%C3\%AAncia\% 20Emocional.pdf, acesso 13 de Mar. 2019.

GOLEMAN, D. Liderança - A inteligência emocional na formação do líder de sucesso. Editora Objetiva. Rio de Janeiro, 2015

GOLEMAN, D. Inteligência segundo Daniel Goleman. Portal da liderança. 2016. Disponível em https://www.portaldalideranca.pt/videos/4603-inteligencia-social-e-liderancasegundo-daniel-goleman, acesso 02 de Set. 2018

LOVELOCK, C. ; WIRTZ, M. A. H. Marketing de serviços: pessoas, tecnologia e estratégia. (7 ed.). São Paulo: Pearson Prentice Hall. Tradução Sônia Midori Yamamoto, 2011

LUSSIER, R. N. ; ACHUA, C. F.. Leadership: theory, application, skill development (2. ed.). Austrália: Thomson, 2004

Revista ENIAC Pesquisa, Guarulhos (SP), V.9, n.2, ago.2020 - jan.2021 
MACIEL, A. P. ; SOUZA, B. S. Liderança e inteligência emocional: Ferramentas de apoio ao modelo de excelência em gestão pública (2016), Disponivel em https://app.uff.br/riuff/bitstream/1/2207/1/Andreza\%20Paiva-Benjamin\%20S\%C3\%A1.pdf, acesso 04 de Nov. 2018

SBIE. Lotus inteligência emocional (2019). Disponível em https://lp.sbie.com.br/metodolotus-

ie/?utm_source=google\&utm_campaign=lotusie\&utm_term $=\% 2 \mathrm{~B}$ treinamento $\% 20 \% 2 \mathrm{Bintelig}$ encia $\% 20 \% 2 B e m o c i o n a l \& u t m \_$medium $=1 \mathrm{t} 2 \& u t m \_c o n t e n t=\&$ gclid=EAIaIQobChMIkfWJ7Z P94QIVjwuRCh0VzQZAEAAYAiAAEgL5RfD_BwE, acesso 30 de abr. 2019

SILVA, E.W. da. Inteligência emocional e sua importância nas lideranças e no trabalho. XII Congresso Nacional de Excelência em Gestão, 29 e 30 setembro de 2016. Rio de Janeiro, RJ, 2016

WEISINGER, H. Inteligência Emocional no Trabalho (12 ed.). Rio de Janeiro: Objetiva, 1997

ZONIS. M. O que acontece na empresa quando o líder não sabe comandar. Revista exame (2016). Disponícel em https://exame.abril.com.br/pme/o-que-acontece-na-empresa-quando-olider-nao-sabe-comandar/ , acesso 13 de Mar. de 2019.

Revista ENIAC Pesquisa, Guarulhos (SP), V.9, n.2, ago.2020 - jan.2021 